\title{
A FORMAÇÃO \\ SOCIOAMBIENTAL DO TÉCNICO \\ EM MANUTENÇÃO E SUPORTE \\ EM INFORMÁTICA EGRESSO DO \\ INSTITUTO FEDERAL DE \\ SERGIPE CAMPUS SOCORRO
}

Lucas Antonio Feitosa de Jesus ${ }^{1}$

Resumo: $O$ presente artigo investigou os conhecimentos, as opiniões, as habilidades e as atitudes socioambientais em Tecnologia da Informação dos egressos do ano de 2019 oriundos do curso técnico em Manutenção e Suporte em Informática do Instituto Federal de Sergipe Campus Socorro. Mediante pesquisa quantitativa com a utilização de um questionário em Escala de Lickert, foi verificado um cenário adverso no processo educativo desses egressos, observando-se uma baixa compreensão teórico-prática de princípios da sustentabilidade ambiental associados à Tecnologia da Informação. Sugere-se, para o curso pesquisado, a aplicação de conteúdos e métodos que preparem profissionais integralmente formados e socioambientalmente conscientes.

Palavras-chave: Formação Humana Integral; Educação Profissional e Tecnológica; Educação Ambiental; Tecnologia da Informação; TI Verde.

Abstract: This article investigated the socioenvironmental knowledges, opinions, skills and attitudes in Information Technology of the graduates of the year 2019 from the technical course in Maintenance and Support in Informatics at the Federal Institute of Sergipe Campus Socorro. Through a quantitative research using a questionnaire on the Lickert Scale, an adverse scenario was found in the educational process of these graduates, with a low theoretical-practical understanding of the principles of environmental sustainability associated with Information Technology. It is suggested, for the researched course, the application of contents and methods that prepare integral and socioenvironmentally consciously professionals.

Keywords: Integral Human Formation; Professional and Technological Education; Environmental Education; Information Technology; Green IT.

${ }^{1}$ Instituto Federal de Educação, Ciência e Tecnologia de Sergipe Campus Socorro. E-mail: lucas.jesus@ifs.edu.br. Link para o Lattes: http://lattes.cnpq.br/0241041439705055.

Revbea, São Paulo, v.16, № 1: 240-262, 2021. 


\section{Introdução}

Por intermédio da Lei no 11.892 de 29 de dezembro de 2008, o governo federal brasileiro - através do Ministério da Educação - instituiu em âmbito nacional a Rede Federal de Educação Profissional, Científica e Tecnológica (RFEPCT). No conjunto de instituições de ensino que a compõem, os Campi dos Institutos Federais de Educação, Ciência e Tecnologia (IF) correspondem à maior fatia de entidades associadas à RFEPCT, recebendo, portanto, notoriedade no desenvolvimento da Educação Profissional e Tecnológica (EPT) como processo educativo e investigativo para 0 atendimento das demandas sociais em conformidade com as particularidades regionais (BRASIL, 2008). De acordo com Pacheco (2011, p. 12),

Os Institutos Federais de Educação, Ciência e Tecnologia são a síntese daquilo que de melhor a Rede Federal construiu ao longo de sua história e das políticas de educação profissional e tecnológica do governo federal. São caracterizados pela ousadia e inovação necessárias a uma política e a um conceito que pretendem antecipar aqui e agora as bases de uma escola contemporânea do futuro e comprometida com uma sociedade radicalmente democrática e socialmente justa.

Como base para a construção de um projeto educacional dessa natureza, a constituição identitária da Educação Profissional e Tecnológica desenvolvida nos Institutos Federais procura afastar-se de um ensino que atenda única e exclusivamente às exigências do mercado, fundamentando-se em um modelo pedagógico que fomenta a integração da cultura, do trabalho, da ciência e da tecnologia tendo como meta a omnilateralidade na formação dos trabalhadores. Essa concepção de formação humana integral, como explicam Araújo e Frigotto (2015), condiz com uma proposta integradora de ensino profissional que busca a superação da divisão social do trabalho entre a ação de executar e a ação de pensar, o ato de fazer e o ato de planejar. Nesse sentido, os Institutos Federais almejam construir o sujeito omnilateral, ou seja, um profissional formado para o mundo do trabalho, dotado de uma leitura totalizante da realidade e apto a compreender as relações sociais, os valores históricos e os aspectos ético-políticos latentes à totalidade dos fenômenos humanos. Em outras palavras, o ensino profissional e tecnológico promovido pelos Institutos Federais, à luz dos objetivos de formação humana integral, deve estar alinhado para que:

a) conceba o sujeito como ser histórico-social concreto, capaz de transformar a realidade em que vive; b) vise à formação humana como síntese de formação básica e formação para o trabalho; c) tenha o trabalho como princípio educativo no sentido de que o trabalho permite, concretamente, a compreensão do significado econômico, social, histórico, político e cultural das ciências e das artes; d) seja baseado numa epistemologia que considere a unidade de 
conhecimentos gerais e conhecimentos específicos [...]; e) seja baseado numa pedagogia que vise a construção conjunta de conhecimentos gerais e específicos, [...]; f) seja centrado nos fundamentos das diferentes técnicas que caracterizam 0 processo do trabalho moderno, tendo como eixos o trabalho, a ciência e a cultura (RAMOS, 2012, p. 109-110).

Com o propósito de estabelecer e aperfeiçoar continuamente o projeto da formação humana integral, é primacial que os Institutos Federais concebam estratégias didático-pedagógicas de fomento ao senso crítico e à compreensão da totalidade dos valores humanos. Por esse ângulo, Jesus (2020) afirma ser possível considerar a Educação Ambiental como uma dessas estratégias, visto que seu caráter interdisciplinar e transversal pode proporcionar uma práxis educativa passível de associar o conhecimento técnico-científico aos demais aspectos da vida humana. Em suma, é plausível presumir que a interpretação da realidade mediante as particularidades comuns à existência do ser humano e à complexidade das questões ambientais pode ser um promissor itinerário a ser seguido pela EPT desenvolvida nos IF.

Não se limitando a inferências de caráter teórico-epistemológico, a inserção da Educação Ambiental na Educação Profissional e Tecnológica também encontra respaldo em documentos legais. No $3^{\circ}$ parágrafo do seu artigo 10ㅜㅡ, a Política Nacional de Educação Ambiental estabelece como uma de suas normas que "nos cursos de formação e especialização técnicoprofissional, em todos os níveis, deve ser incorporado conteúdo que trate da ética ambiental das atividades profissionais a serem desenvolvidas" (BRASIL, 1999, p. 3); ratificando-a, as Diretrizes Curriculares Nacionais para a Educação Ambiental trazem, em seu artigo $9^{\circ}$, que "nos cursos de formação inicial e de especialização técnica e profissional, em todos os níveis e modalidades, deve ser incorporado conteúdo que trate da ética socioambiental das atividades profissionais" (BRASIL, 2012, p. 3).

Ao analisar o Catálogo Nacional de Cursos Técnicos - compêndio oficial da Secretaria de Educação Profissional e Tecnológica que detalha a oferta de cursos de educação profissional técnica de Nível Médio -, especificamente no que diz respeito aos cursos do eixo Informação e Comunicação, é possível observar que a orientação quanto à articulação da Educação Ambiental na EPT é, não só contemplada, como também acrescida de outros conhecimentos e habilidades complementares.

A organização curricular dos cursos contempla conhecimentos relacionados a: leitura e produção de textos técnicos; estatística e raciocínio lógico; ciência, tecnologia e inovação; investigação tecnológica; empreendedorismo; desenvolvimento interpessoal; legislação; normas técnicas; saúde e segurança no trabalho; gestão da qualidade; responsabilidade $\mathbf{e}$ sustentabilidade social e ambiental; qualidade de vida; e ética profissional (BRASIL, 2016, p. 97, grifo nosso).

Revbea, São Paulo, v.16, № 1: 240-262, 2021. 
Um dos cursos integrantes desse eixo tecnológico é o de técnico em Manutenção e Suporte em Informática (MSI). A despeito das particularidades técnicas que perfazem seu itinerário formativo, o curso técnico em MSI é dotado de condições teórico-práticas alinhadas à promoção de ações didáticopedagógicas em Educação Ambiental, tornando-o potencialmente capaz de fundamentar a conduta do futuro profissional ao desenvolvimento sustentável e à responsabilidade socioambiental. Santos (2016) esclarece que, pelo fato de formar trabalhadores que estarão atuando na linha de frente da Tecnologia da Informação e por ser um curso em voga na maioria das unidades dos Institutos Federais, é impreterível que o curso de MSI possua uma abordagem dos conteúdos técnicos específicos relacionando-os à Educação Ambiental, à cidadania e à sustentabilidade ambiental, tendo na interdisciplinaridade um ponto-chave para ações formativas coordenadas e orientadas pelo interesse compartilhado dos alunos.

O curso de Manutenção e Suporte em Informática sinaliza para uma particular combinação de conhecimentos e habilidades necessárias em alunos e que proporcione uma experiência por meio da relação teoria e prática a competência no desempenho, na eficácia e no atendimento dos anseios do setor produtivo. Como também cria soluções a partir da participação da comunidade acadêmica, o aprofundamento de estudos necessários ao contorno de soluções ambientais. Em virtude de sua qualificação profissional, em que técnicos mobilizam resolução para determinados problemas, em especial, a manutenção de computadores (SANTOS, 2016, p. 41).

Neste cenário de consonância entre as questões ambientais e a Tecnologia da Informação, é precípuo que se recorra ao conceito de Tecnologia da Informação Verde ou, simplesmente, TI Verde. Conforme Murugesan (2010), a TI Verde corresponde às práticas e aos estudos destinados a projetar, fabricar, usar e descartar computadores e subsistemas associados - tais como monitores, impressoras, dispositivos de armazenamento e sistemas de rede e comunicação - de modo ecologicamente eficiente, com impacto mínimo ou nenhum sobre o meio ambiente, empenhando-se também em alcançar a viabilidade econômica e melhorar 0 desempenho dos produtos tecnológicos, reforçando os pilares da ética e da responsabilidade socioambiental. Trazendo este conceito à realidade educacional da EPT e dos IF, tendo sempre em mente a proposta da omnilateralidade, Jesus (2020) afirma que o conjunto de temas que compõem a TI Verde formam um complexo temático integrador propício aos pressupostos de uma formação integral, crítica e humanista.

Isto posto, o presente artigo buscou investigar os conhecimentos, as opiniões, as habilidades e as atitudes dos egressos do ano de 2019 do curso 
técnico subsequente em Manutenção e Suporte em Informática do Instituto Federal de Sergipe (IFS) Campus Socorro no tocante a conceitos e práticas socioambientais aplicados direta ou indiretamente ao universo da TI Verde, caracterizando o perfil desses novos técnicos tendo tais parâmetros como referência.

\section{Metodologia}

O corrente estudo se deu mediante uma pesquisa quantitativa com os egressos dos períodos 2019/1 e 2019/2 do curso técnico subsequente em Manutenção e Suporte em Informática do Instituto Federal de Sergipe Campus Socorro. A escolha pelos egressos para a realização desta investigação se deu pois eles conviveram por mais tempo no ambiente do Instituto, tiveram contato com todas as disciplinas obrigatórias e, em tese, se encontram mais aptos a apresentarem a verossimilhança do perfil socioambiental do aluno que se forma pelo IFS Campus Socorro.

Nesta pesquisa quantitativa, foi elaborado como instrumento de pesquisa um questionário em formato de Escala de Lickert. Essa escala é utilizada para medir opiniões, atitudes, conhecimentos e práticas sociais a partir do grau de concordância ou discordância a respeito deu um determinado número de afirmações (MARCONI; LAKATOS, 2011). Há vários níveis de resposta, mas, para a presente pesquisa, foram definidos cinco, limitando os respondentes a uma posição negativa, indecisa/ocasional ou positiva. Sua aplicação ocorreu ao longo dos meses de maio e outubro de 2019.

Visando responder ao objetivo proposto pelo artigo, esse instrumento de pesquisa foi dividido em quatro partes: 1) aspectos sócio-econômicoculturais dos egressos; 2) conhecimentos e opiniões socioambientais em TI; 3) habilidades socioambientais em Tl; 4) atitudes socioambientais em TI. A ideia é que, através dos resultados, fosse possível identificar: 1) a perspectiva social sobre a qual esses novos técnicos enxergam a realidade e nela atuam; 2) as atitudes e os hábitos de consumo desses egressos; 3) o entendimento particular sobre o que é a TI Verde; 4) a realização de procedimentos específicos e gerais em Tecnologia da Informação vinculados à sustentabilidade ambiental; 5) o consumo consciente; 6) o exercício da cidadania.

Em conformidade com a tabela 1, o questionário recebeu 37 respostas provenientes dos egressos do período 2019/1 e 41 respostas dos egressos do período 2019/2, totalizando 78 respondentes dentre os 86 técnicos que se formaram durante todo 0 ano de 2019. Os dados alusivos à quantidade de técnicos que se formaram em 2019 foram obtidos mediante consulta realizada no Sistema Integrado de Gestão de Atividades Acadêmicas (SIGAA) do Instituto Federal de Sergipe em fevereiro de 2020. 
Tabela 1: Comparação quantitativa entre egressos e respondentes do questionário

\begin{tabular}{ccc}
\hline PERÍODO & EGRESSOS & RESPONDENTES \\
\hline $\mathbf{2 0 1 9 / 1}$ & 40 & 37 \\
\hline $\mathbf{2 0 1 9 / 2}$ & 46 & 41 \\
\hline FREQUÊNCIA ABSOLUTA & 86 & 78 \\
\hline FREQUÊNCIA RELATIVA (\%) & $100 \%$ & $90,7 \%$ \\
\hline
\end{tabular}

Fonte: Elaborado pelo próprio pesquisador.

Os resultados oriundos do questionário foram tratados com a técnica da estatística descritiva e com o auxílio instrumental do Microsoft Office Excel. Tendo como principais componentes os gráficos e as tabelas, bem como medidas de síntese (porcentagem, índices e médias), a estatística descritiva é fundamentalmente utilizada "para organizar, resumir e descrever os aspectos importantes de um conjunto de características observadas ou comparar tais características entre dois ou mais conjuntos" (REIS; REIS, 2002, p. 5). Os dados obtidos foram organizados em tabelas, permitindo que as frequências relativas de cada item fossem independentemente interpretadas.

Para o cálculo das frequências relativas, adotou-se 0 seguinte procedimento matemático: $F R=F A / T R$, onde $\mathrm{FR}=$ frequência relativa, expressa em porcentagem; $F A=$ frequência absoluta, correspondente às respostas efetivas dadas para cada opção dos itens apresentados; TR = total de respondentes, referente à totalidade de indivíduos que responderam aos itens.

\section{Resultados e discussões}

Em concordância com o percurso metodológico adotado para este estudo, a primeira parte do questionário foi destinada ao levantamento de alguns aspectos sócio-econômico-culturais dos egressos pesquisados com o intuito de verificar o prisma que embasa a prática social imediata dos investigados. Como explica Gasparin (2015), essa prática social representa a identidade cultural de um grupo cujas concepções, vivências, percepções e conceitos a respeito de determinado conteúdo estão condicionados à origem social deste grupo. Assim, os resultados desta primeira parte foram condensados na Tabela 2. 
Tabela 2: Caracterização sócio-econômico-cultural dos egressos do ano de 2019 oriundos do curso técnico subsequente em Manutenção e Suporte em Informática do IFS Campus Socorro.

\begin{tabular}{|c|c|c|c|}
\hline ITENS & SUBITENS & $\begin{array}{c}\text { FREQUÊNCIA } \\
\text { ABSOLUTA }\end{array}$ & $\begin{array}{l}\text { FREQUÊNCIA } \\
\text { RELATIVA (\%) }\end{array}$ \\
\hline Sexo & $\begin{array}{l}\text { Feminino } \\
\text { Masculino }\end{array}$ & $\begin{array}{l}23 \\
55\end{array}$ & $\begin{array}{l}29,5 \% \\
70,5 \%\end{array}$ \\
\hline Faixa etária & $\begin{array}{l}\text { Até } 18 \text { anos } \\
\text { De } 19 \text { a } 24 \text { anos } \\
\text { De } 25 \text { a } 34 \text { anos } \\
\text { De } 35 \text { a } 44 \text { anos } \\
\text { De } 45 \text { a } 54 \text { anos } \\
55 \text { anos ou mais }\end{array}$ & $\begin{array}{c}9 \\
47 \\
17 \\
1 \\
4 \\
0\end{array}$ & $\begin{array}{c}11,5 \% \\
60,3 \% \\
21,8 \% \\
1,3 \% \\
5,1 \% \\
0 \%\end{array}$ \\
\hline $\begin{array}{l}\text { Conclusão do } \\
\text { Ensino Médio }\end{array}$ & $\begin{array}{l}\text { Escola pública } \\
\text { Escola particular }\end{array}$ & $\begin{array}{l}62 \\
16\end{array}$ & $\begin{array}{l}79,5 \% \\
20,5 \%\end{array}$ \\
\hline $\begin{array}{l}\text { Trabalha ou } \\
\text { desenvolve alguma } \\
\text { atividade } \\
\text { remunerada }\end{array}$ & $\begin{array}{l}\text { Sim } \\
\text { Não }\end{array}$ & $\begin{array}{l}22 \\
56\end{array}$ & $\begin{array}{l}28,2 \% \\
71,8 \%\end{array}$ \\
\hline $\begin{array}{l}\text { Renda mensal } \\
\text { familiar } \\
\text { (considerando o } \\
\text { salário mínimo de } \\
\text { R } \$ 998,00 \text { conforme } \\
\text { a vigência de 2019) }\end{array}$ & $\begin{array}{l}\text { Até } 1 \text { salário mínimo } \\
\text { Até } 2 \text { salários mínimos } \\
\text { De } 3 \text { a } 5 \text { salários mínimos } \\
\text { Mais que } 5 \text { salários mínimos }\end{array}$ & $\begin{array}{c}44 \\
22 \\
10 \\
2\end{array}$ & $\begin{array}{c}56,4 \% \\
28,2 \% \\
12,8 \% \\
2,6 \%\end{array}$ \\
\hline
\end{tabular}

Fonte: Elaborado pelo próprio pesquisador.

De acordo com as informações evidenciadas pela tabela supracitada, é possível inferir que, além de indicar uma representação do fenômeno da sexualização ou gendramento de carreiras - conceito este que remete à escassa presença feminina em cursos masculinamente estereotipados, especialmente aqueles relacionados às Ciências Exatas, Engenharias e Computação (QUEIROZ; CARVALHO; MOREIRA, 2014) -, o curso técnico de Manutenção e Suporte em Informática do IFS Campus Socorro está de acordo com o objetivo histórico da Educação Profissional e Tecnológica no Brasil, isto é, o amparo educacional àqueles que não possuem condições sociais satisfatórias (BRASIL, 2007). Levando em conta essas breves considerações, prosseguir-se-á ao cerne deste artigo.

\section{Conhecimentos e opiniões socioambientais em TI}

Com o intuito de mapear o universo teórico e a sensibilização conceitual dos egressos quanto às questões socioambientais relacionadas à $\mathrm{TI}$, foram analisados os conhecimentos e as opiniões dos novos técnicos acerca de temas da TI Verde, sendo destacados, em negrito, os dois valores percentuais mais representativos por item. Parte-se do seguinte pressuposto: os saberes e as convicções socioambientais em TI encontram-se na base da aprendizagem relativa à $\mathrm{TI}$ Verde, à qual os egressos teriam se apropriado significativamente caso lhes fosse fornecido o contato direto ou indireto com seu conteúdo. De acordo com Santos (2016), o fundamento às ações socioambientais dos egressos - tanto enquanto cidadãos, como enquanto 
técnicos em $\mathrm{MSI}$ - se dá em conformidade com as informações de que dispõem.

Tabela 3: Frequência relativa (\%) das respostas referentes aos conhecimentos e às opiniões socioambientais em TI dos egressos pesquisados

\begin{tabular}{l}
\hline \multicolumn{1}{c}{ ITENS } \\
\hline 1. Ser responsável pelo meio \\
ambiente é um dever de todos. \\
2. Quanto mais Tecnologia, mais \\
progresso para a humanidade.
\end{tabular}

3. Toda ação é válida quando se trata de ter sucesso nos negócios e maximizar os lucros.

4. Conhecer a origem dos produtos tecnológicos que utilizamos é muito importante pois sua produção pode ter causado danos para o meio ambiente e para a sociedade.

5. É importante sempre possuir equipamentos eletrônicos de última geração.

6. Plástico, vidro, metais e placas são os principais componentes de computadores que podem ser reciclados.

7. Trade-in, logística reversa e economia circular fazem parte do Gerenciamento dos Resíduos Elétricos e Eletrônicos.

8. Os metais pesados contidos em peças de computadores podem causar sérios problemas de saúde quando descartados indevidamente na natureza.

9. Quando um equipamento eletrônico vira lixo eletrônico, seu melhor destino é a desmanufatura para retirada dos seus componentes tóxicos e reciclagem de cada um dos seus materiais.

10. É importante controlar a quantidade de material impresso.

\begin{tabular}{|c|c|c|c|c|}
\hline$\overline{\mathrm{DT}^{1}}$ & $\overline{D^{2}}$ & $\mathrm{NS}^{3}$ & $\overline{C^{4}}$ & $\mathrm{CT}^{5}$ \\
\hline $1,3 \%$ & $0 \%$ & $2,6 \%$ & $12,8 \%$ & $83,3 \%$ \\
\hline $0 \%$ & $2,6 \%$ & $20,5 \%$ & $30,8 \%$ & $46,1 \%$ \\
\hline $12,8 \%$ & $8,9 \%$ & $10,3 \%$ & $30,8 \%$ & $37,2 \%$ \\
\hline $10,2 \%$ & $9 \%$ & $60,2 \%$ & $12,8 \%$ & $7,7 \%$ \\
\hline $14,1 \%$ & $21,8 \%$ & $26,9 \%$ & $24,4 \%$ & $12,8 \%$ \\
\hline $1,3 \%$ & $3,8 \%$ & $56,4 \%$ & $26,9 \%$ & $11,6 \%$ \\
\hline $1,3 \%$ & $6,4 \%$ & $48,7 \%$ & $23,1 \%$ & $20,5 \%$ \\
\hline $1,3 \%$ & $2,6 \%$ & $44,9 \%$ & $26,9 \%$ & $24,3 \%$ \\
\hline $1,3 \%$ & $1,3 \%$ & $55,1 \%$ & $32 \%$ & $10,3 \%$ \\
\hline $0 \%$ & $1,3 \%$ & $41 \%$ & $46,1 \%$ & $11,6 \%$ \\
\hline
\end{tabular}

Revbea, São Paulo, v.16, № 1: 240-262, 2021. 
...continuação.

\begin{tabular}{l}
\hline ITENS \\
\hline 11. Centralização de impressoras e \\
habilitação da impressão em \\
modo econômico (ecoprint) são \\
alternativas para a redução de \\
energia e de gastos com papel.
\end{tabular}

12. A emissão de gás carbônico (um dos principais causadores do efeito estufa) está diretamente relacionada ao consumo de energia elétrica.

13. Virtualização, consolidação ou centralização de servidores, cloud computing e uso de thin clients são algumas das ações em TI que ajudam a reduzir os gastos com energia elétrica.

14. Monitores do tipo Liquid Crystal Display (LCD) consomem menos energia do que os do tipo Cathodic-Ray Tube (CRT).

15. Datacenters correspondem ao conjunto de equipamentos de TI que mais consomem energia elétrica.

16. É possível aplicar a Educação Ambiental e a sustentabilidade ambiental em atividades de Tecnologia da Informação.

17. A prática profissional do técnico em Manutenção e Suporte em Informática pode estar vinculada à sustentabilidade ambiental.

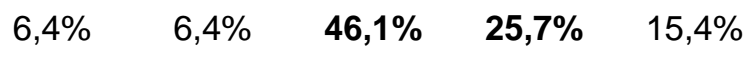

$0 \% \quad 2,6 \% \quad \mathbf{5 7}, \mathbf{7} \% \quad \mathbf{2 1 , 8} \% \quad \mathbf{1 7 , 9} \%$

$1,3 \% \quad 1,3 \% \quad \mathbf{4 1} \% \quad \mathbf{3 2} \% \quad 24,4 \%$

$1,3 \% \quad 1,3 \% \quad \mathbf{4 6 , 1} \% \quad 23,1 \% \quad \mathbf{2 8 , 2} \%$

$2,6 \% \quad \mathbf{2 3}, \mathbf{1} \% \quad \mathbf{6 0}, \mathbf{2} \% \quad 11,5 \% \quad 2,6 \%$

$1,3 \% \quad \mathbf{2 4 , 4} \% \quad \mathbf{6 1 , 5} \% \quad \mathbf{1 0}, 2 \% \quad 2,6 \%$

1- Discordo Totalmente; 2- Discordo; 3- Não sei; 4- Concordo; 5- Concordo Totalmente.

Fonte: Elaborado pelo próprio pesquisador.

O alto índice de concordância em relação ao item 1 denota uma aproximação dos investigados à conscientização ambiental. A partir tão somente deste item, seria possível presumir que os egressos do curso técnico em MSI do IFS Campus Socorro demonstram possuir uma percepção, ao menos mínima, acerca da importância dos valores ambientais na vida cotidiana, havendo, portanto, uma associação positiva entre a aprendizagem das questões ambientais e o percurso formativo desses ex-alunos.

Porém, o simples fato de esse posicionamento ser apresentado pela maioria dos pesquisados, não significa de modo inconteste que esses egressos 
possuam, peremptoriamente, uma racionalidade crítico-reflexiva e uma postura ética, responsável e cidadã no tocante ao meio ambiente. O resultado apresentado neste item pode ser uma mera reprodução de um ideal pré-fixado pelo senso comum que não simboliza, como explica Paula (2016, p. 22), uma "reflexão, a fim de que o estudante saia da zona de conforto alienadora e se mova em direção a uma práxis transformadora”.

Essa conduta acrítica ficou especialmente visível nas respostas fornecidas aos itens 2 e 3. A concordância majoritária nesses itens indica, não apenas uma tendência à limitadora lógica do pensamento econômico e da valorização do capital (ANTUNES, 2009), como também uma adesão dos egressos ao Modelo Linear de Progresso (AULER, 2007). Nesse modelo, há uma concepção do desenvolvimento científico, tecnológico e econômico a partir de um padrão determinista e unidirecional ao bem-estar social, privilegiando-se decisões tecnocráticas em detrimento de apreciações críticas sobre os demais elementos sócio-históricos que compõem esse processo. A dimensão ambiental, com as constantes mudanças que a tecnologia causa ao contexto social e ao meio ambiente, corresponde a um dos elementos olvidados por essa perspectiva.

A distribuição percentual verificada no item 5 também aponta que a maior parte dos egressos investigados provavelmente é desprovida da condição de omnilateralidade. Antunes (2009) defende que na atual fase de mundialização do capitalismo, caracterizada pela transnacionalização do capital e do seu sistema produtivo, observa-se o estabelecimento de uma configuração social que dificulta o surgimento de uma subjetividade autêntica dos trabalhadores. As muitas formas de fetichizações e reificações pautadas pela voracidade das perspectivas mercadológicas, acabam por colonizar o mundo do trabalho e as demais esferas da reprodução social, "onde o consumo de mercadorias, materiais e imateriais, também está em enorme medida estruturado pelo capital' (ANTUNES, 2009, p. 131). Os valores percentuais percebidos neste e nos dois últimos itens anteriormente citados, embora não sejam categóricos para confirmar a ausência absoluta da formação humana integral entre os egressos investigados, indicam, ao menos, que essa formação não foi totalmente constatada entre os sujeitos de pesquisa.

Jesus (2020) explica que a redução dos resíduos de equipamentos elétricos e eletrônicos (REEE) constitui-se como uma das principais categorias de ação da TI Verde. Silva (2018) afirma que os REEE são considerados um dos maiores problemas ambientais do mundo na atualidade. Esses resíduos, uma vez descartados no ambiente sem qualquer tipo de tratamento, representam um grave risco para a natureza. Eles têm, em sua composição, metais pesados e altamente tóxicos como mercúrio, cádmio, berílio e chumbo. Ao entrarem em contato com o solo, esses metais podem contaminar os lençóis freáticos e, se incinerados, poluem o ar. As substâncias contidas nos REEE, quando inaladas ou ingeridas, podem provocar distúrbios no sistema nervoso, problemas renais, enfermidades pulmonares, câncer e danos ao cérebro. 
A formação do técnico em Manutenção e Suporte em Informática aproxima-se da problemática do lixo eletrônico (SANTOS, 2016). Desta forma, as especificidades técnicas do seu itinerário formativo podem ser complementadas por temáticas transversais e integradoras provenientes da TI Verde que discutam informações relevantes sobre os impactos dos REEE no meio ambiente e na saúde humana. Conhecer quais elementos compõem os aparelhos elétricos e eletrônicos, os efeitos que eles causam no organismo humano, onde eles localizam-se nos equipamentos informáticos, detalhes sobre a realidade global dos REEE e metodologias para o recolhimento de aparelhos antigos são alguns temas potencialmente capazes de serem desenvolvidos de maneira integrada em um curso técnico de MSI.

Porém, a maior parte dos egressos pesquisados revelaram uma insuficiência teórica neste tópico. Os maiores valores percentuais dos itens 6 e 9 registraram uma incerteza de entendimento dos técnicos recém-formados às afirmações apresentadas. Os itens 7 e 8 , embora tenham evidenciado uma distribuição mais equilibrada entre o desconhecimento sobre as assertivas e a somatória das concordâncias, também apontaram para uma maioria de egressos associada à incerteza.

O aumento exponencial da quantidade de resíduos de equipamentos elétricos e eletrônicos ao redor do mundo possui como origem predominante os avanços tecnológicos contínuos aliados ao ímpeto consumista e à célere obsolescência dos aparelhos (JESUS, 2020). A alienação presente na subjetividade dos trabalhadores - dentre os quais são incluídos, sobretudo, aqueles oriundos da Educação Profissional - e as objetivações fetichizadas que a eles são impostas pelo capital (ANTUNES, 2009), são o cerne de ações irrefletidas, como, por exemplo, o consumo pelo consumo. Nesse sentido, as respostas ao item 4 também identificaram uma incerteza na compreensão da maior parte dos egressos quanto à necessidade da aplicação de critérios sociais e ambientais no momento da aquisição de produtos tecnológicos.

Os subprodutos provenientes indiretamente do lixo eletrônico também são alvos dos procedimentos destinados à redução dos REEE. Um dos principais subprodutos dessa natureza é o papel. Batista (2018) esclarece que o desperdício de papel é uma preocupação constante, não apenas daqueles que desejam efetivar ações de proteção ambiental com vistas à diminuição do custo financeiro em seus respectivos empreendimentos, como também e, principalmente, de indivíduos e coletivos de pessoas empenhados em conter os vultosos prejuízos ambientais causados pela sua produção. Ainda conforme Batista (2018), a cadeia produtiva de $250 \mathrm{~kg}$ a $300 \mathrm{~kg}$ de papel conduz, por ano, a derrubada de aproximadamente $40 \%$ das árvores do mundo destinadas a esse fim; outrossim, a fabricação de 1 tonelada de papel libera na atmosfera cerca de 1,5 tonelada de $\mathrm{CO}_{2}$.

Destarte, dos itens que trataram do controle de impressões e dos gastos com papel, mais da metade dos novos técnicos pesquisados posicionaram-se em dúvida na afirmação apresentada pelo item 11; no item 10, apesar de a maior porcentagem assinalar concordância, chamou atenção a Revbea, São Paulo, v.16, № 1: 240-262, 2021. 
grande quantidade de egressos que igualmente demonstraram incerteza no enunciado. Muito possivelmente, conteúdos que discutam a redução no uso de papel, desde atitudes gerenciais e técnicas a ações estratégicas de cidadania, não são suficientemente abordados na formação do técnico em MSI do IFS Campus Socorro.

O item 11 introduz as questões referentes a outra categoria de ação da TI Verde identicamente fundamental: o gerenciamento de energia elétrica (JESUS, 2020). Estudos recentes realizados pelo think tank francês The Shift Project (https://theshiftproject.org/en/home/), informam que o ritmo de gasto energético com $\mathrm{TI}$ segue crescendo a passos largos: a cada ano, 9\% a mais de energia elétrica vinculada às Tecnologias da Informação é despendida. Segundo essa organização, em 2018 o consumo de energia elétrica procedente do uso e da produção de equipamentos de TI representou cerca de $3,7 \%$ das emissões globais dos gases de efeito estufa, o que equivale a 830 milhões de toneladas desses poluentes.

Conforme Santos et al. (2017), a formação do profissional em Manutenção e Suporte em Informática também pode ser contemplada por conteúdos que, transversal e integradamente, proponham reflexões críticas quanto ao consumo consciente de eletricidade como, por exemplo: compreender quais softwares e hardwares são mais sustentáveis e de que modo eles podem atuar como sistemas de economia de energia; saber quais componentes de um computador gastam mais energia e quais atitudes devem ser tomadas para que se reduza o gasto energético nestes equipamentos; conhecer as fontes alternativas de energia e quais delas são ambientalmente menos agressivas; entender como a TI contribui com o aquecimento global e buscar meios para reduzir esse impacto; analisar como a heterogênea distribuição global de eletricidade e as distintas possibilidades de acesso aos bens de consumo de $\mathrm{Tl}$ entre os povos podem ser parâmetros para se avaliar a desigualdade social.

Todavia, as maiores porcentagens dos itens 12 e 13 permaneceram no nível do desconhecimento das afirmativas, indicando que a maioria dos egressos pesquisados não alcançaram um razoável entendimento sobre assuntos específicos deste tema. Os itens 14 e 15, conquanto tenham evidenciado valores de equilíbrio entre a incerteza em relação às assertivas e a somatória das concordâncias, similarmente indicaram que a maior parte dos novos técnicos não possui contundente domínio sobre determinados tópicos que compõem o gerenciamento de energia elétrica.

Finalmente, as respostas obtidas nos itens 16 e 17 constataram que os egressos pesquisados, em sua maior parte, não têm certeza se a área de conhecimento à qual pertencem e se sua futura atuação profissional enquanto técnicos em Manutenção e Suporte em Informática possuem identificação com as questões ambientais. Presume-se que esse quadro reflita uma ausência de ações e práticas pedagógicas sólidas da TI Verde no IFS Campus Socorro em 
favor de sua abordagem indireta, superficial, inconsciente e desprovida das multiplicidades de dimensões que lhes são próprias.

\section{Habilidades socioambientais em TI}

As habilidades ora examinadas correspondem aos procedimentos específicos na área de TI, passíveis de execução no curso técnico de Manutenção e Suporte em Informática e que detêm, ao mesmo tempo, influência direta no meio ambiente. Tal como realizado na análise dos conhecimentos e das opiniões socioambientais em TI, dentre as porcentagens aqui obtidas foram destacadas, em negrito, as duas numericamente mais representativas por item.

Tabela 4: Frequência relativa (\%) das respostas referentes às habilidades socioambientais em TI dos egressos pesquisados

\begin{tabular}{l}
\hline ITENS \\
\hline 18. Configuro meu computador ou o \\
computador do meu trabalho para \\
desligar automaticamente quando me \\
ausento por muito tempo.
\end{tabular}

19. Programo meu computador ou o computador do meu trabalho para entrar no descanso de tela sempre que preciso me ausentar por pouco tempo.

20. Configuro meu computador ou o computador do meu trabalho para economia de energia através de algumas modificações em seus sistemas operacionais.

21. Para calcular e aumentar a eficiência energética de um datacenter, utilizo o método matemático Power Usage Effectiveness (PUE) e/ou programas de Data Center Infraestructure Management (DCIM).

22. Costumo utilizar softwares para 0 gerenciamento de energia dos aparelhos eletrônicos sob minha responsabilidade.

23. Priorizo a construção e o uso de máquinas virtuais, com funções análogas às máquinas físicas, de modo a atenuar tanto o gasto de energia elétrica como a produção de lixo eletrônico.

\begin{tabular}{ccccc}
$\mathbf{N}^{1}$ & $\mathbf{R}^{\mathbf{2}}$ & $\mathbf{A V}^{\mathbf{3}}$ & $\mathbf{F}^{\mathbf{4}}$ & $\mathbf{S}^{5}$ \\
\hline $\mathbf{3 2} \%$ & $\mathbf{2 5 , 7 \%}$ & $21,8 \%$ & $11,5 \%$ & $9 \%$ \\
& & & & \\
& & & & \\
$\mathbf{3 0 , 8} \%$ & $\mathbf{2 6 , 9} \%$ & $24,3 \%$ & $10,3 \%$ & $\mathbf{7 , 7} \%$ \\
& & & & \\
& & & & \\
& & & & \\
$\mathbf{2 3 , 1} \%$ & $\mathbf{3 0 , 8} \%$ & $20,5 \%$ & $14,1 \%$ & $11,5 \%$
\end{tabular}

$\begin{array}{lllll}87,2 \% & 9 \% & 3,8 \% & 0 \% & 0 \%\end{array}$

$23,1 \% \quad 29,5 \% \quad 26,9 \% \quad 12,8 \% \quad 7,7 \%$

$\mathbf{8 2 , 1} \% \quad \mathbf{1 0 , 2} \% \quad 6,4 \% \quad 1,3 \% \quad 0 \%$ 
...continuação.

\begin{tabular}{|c|c|c|c|c|c|}
\hline ITENS & $\mathbf{N}^{1}$ & $\overline{\mathrm{R}^{2}}$ & $\overline{A V^{3}}$ & $\mathrm{~F}^{4}$ & $\mathrm{~S}^{5}$ \\
\hline $\begin{array}{l}\text { 24. Em um computador, durante o processo } \\
\text { de manutenção e manuseio das peças, } \\
\text { diferencio os componentes que podem } \\
\text { ser reciclados ou reutilizados daqueles } \\
\text { que devem ser descartados. }\end{array}$ & $17,9 \%$ & $48,7 \%$ & $20,5 \%$ & $7,7 \%$ & $5,1 \%$ \\
\hline $\begin{array}{l}\text { 25. Configuro minha impressora ou a } \\
\text { impressora do meu trabalho para } 0 \\
\text { modo duplex. }\end{array}$ & $42,3 \%$ & $14,1 \%$ & $29,5 \%$ & $6,4 \%$ & $7,7 \%$ \\
\hline $\begin{array}{l}\text { 26. Digitalizo documentos visando reduzir o } \\
\text { uso de papel. }\end{array}$ & $17,9 \%$ & $28,2 \%$ & $26,9 \%$ & $15,4 \%$ & $11,5 \%$ \\
\hline $\begin{array}{l}\text { 27. Antes de comprar ou recomendar um } \\
\text { equipamento, verifico se ele possui } \\
\text { alguma certificação } \\
\text { sustentabilidade/selo verde (LEED, } \\
\text { PROCEL, ISO } 14001 \text {, Energy Star, etc) } \\
\text { ou se atende às legislações ambientais } \\
\text { específicas como, por exemplo, a } \\
\text { Política Nacional de Meio Ambiente (Lei } \\
\text { no } 6.938 / 81 \text {, a Política Nacional de } \\
\text { Resíduos Sólidos (Lei no 12.305/10), a } \\
\text { RoHS (Diretiva da Comunidade Europeia } \\
\text { 2002/95/CE) ou a WEEE (Diretiva da } \\
\text { Comunidade Europeia 2002/96/CE). }\end{array}$ & $47,4 \%$ & $11,5 \%$ & $19,2 \%$ & $15,4 \%$ & $6,4 \%$ \\
\hline
\end{tabular}

1- Nunca; 2- Raramente; 3- Às vezes; 4- Frequentemente; 5- Sempre.

Fonte: Elaborado pelo próprio pesquisador.

Como defendem Santos et al. (2017, p. 47), o estudo sobre o uso racional de energia elétrica em um curso técnico de MSI deve oportunizar situações empíricas que disponham de uma "abordagem lógica, sequencial, com uma análise sistemática das alternativas e suas consequências". Por essa perspectiva, no caso dos computadores, é viável reduzir drasticamente seu consumo de energia fazendo sutis alterações em seus sistemas operacionais. Muitos personal computers permanecem funcionando mesmo quando não estão sendo usados, o que representa um gasto de energia que poderia ser facilmente evitado. Ademais, não apenas o computador per si gasta energia elétrica, mas, mantê-lo funcionando em alta performance, requer também a presença de aparelhos refrigeradores de ar, o que aumenta o dispêndio total de energia.

Acar (2017) esclarece que a redução do consumo de eletricidade pelos computadores pode ser feita mediante recursos de gerenciamento de energia elétrica. Sem afetar o seu desempenho, o computador pode ser programado para, por exemplo, ser desativado automaticamente em ocasiões de ociosidade. Nos sistemas operacionais modernos, é possível utilizar o recurso ACPI (Advanced Configuration and Power Interface), que incorpora sistemas 
de economia de energia, programa o modo de hibernação, permite configurar monitores e discos rígidos para desligarem após um período de tempo em inatividade e evita o funcionamento de outros componentes - como o processador e a memória RAM - quando a máquina estiver inoperante. Murugesan (2010) informa que medidas como essa reduzem em até $70 \%$ o gasto mensal de energia elétrica em um computador frequentemente ativo.

Acar (2017) acrescenta que, para a manutenção das funcionalidades computacionais com redução do consumo energético, é fundamental o uso de softwares sustentáveis. É possível definir um software sustentável como um aplicativo programado eficiente em termos energéticos, que ajuda a minimizar o impacto ambiental dos processos computacionais em que atua e que gera efeitos positivos na sustentabilidade ambiental e econômica. Eles podem se fazer presentes como base da interconexão digital e da automação de máquinas que lidam diretamente com a temperatura, a iluminação e a energia do aparelho em si e dos componentes menores que integram esses equipamentos.

Os limitados conhecimentos da maioria dos egressos sobre o gerenciamento de energia elétrica, à luz dos dados observados na tabela 3 , parecem refletir em suas respectivas ações específicas à profissão. As porcentagens obtidas nos itens 18, 19, 20 e 22 podem indicar que uma considerável parcela dos egressos pesquisados não possui habilidades para executar as operações que Ihes foram apresentadas. Em contrapartida, é necessário pontuar que os resultados alcançados nestes itens também podem ser decorrentes das condições financeiras adversas e do desemprego que, como foi relatado na tabela 2, estão presentes entre esses egressos. Nessa situação, tanto a maturidade como a experiência prática com a TI são comprometidas, uma vez que se torna difícil a obtenção pessoal de algum aparelho computacional ou o acesso a esses instrumentos em ambientes de trabalho.

Ainda no âmbito dos temas referentes ao racionamento de energia elétrica na $\mathrm{TI}$, é preciso mencionar que os datacenters são os principais responsáveis no gasto de eletricidade em Tecnologia da Informação. Dias (2015) explica que a evolução da internet provocou um rápido crescimento destes centros computacionais, fazendo com que as empresas instalassem mais servidores e expandissem sua capacidade de processar os dados com maior celeridade. $O$ conceito clássico de um datacenter bem estruturado e com tecnologia de ponta, exige uma demanda energética muito grande para a aparelhagem, além da climatização necessária para que os servidores não superaqueçam, permitindo-os rodar perfeitamente.

A melhoria da eficiência energética de um datacenter passa, principalmente, pelo controle do seu sistema de resfriamento. De acordo com Lunardi, Simões e Frio (2014), a refrigeração corresponde a 37\% do gasto total de energia em um datacenter, ficando atrás apenas dos servidores, que respondem por $50 \%$ desse montante. Dias (2015) detalha que a forma mais 
eficiente para economizar com a climatização de um datacenter é a partir de softwares de gerenciamento e controle de refrigeração, dentre os quais merecem destaque os programas de Data Center Infraestructure Management (DCIM).

Outra forma de gestão da eletricidade em um datacenter é através de uma métrica de eficiência chamada Power Usage Effectiveness (PUE). Basicamente o cálculo se dá na relação entre a energia consumida pela instalação inteira do datacenter e a energia consumida pelos equipamentos da infraestrutura específica de TI: PUE = ETD / ETI, em que ETD = energia total do datacenter em $\mathrm{kWh}$, a qual parte é perdida e transformada em calor e outra parte é destinada a outros aparelhos como ares-condicionados, lâmpadas e equipamentos de segurança; e ETI = energia total dos aparelhos de TI do datacenter em kWh, direcionada estritamente aos servidores, roteadores, storages, switches e demais instrumentos de TI. Nesse cálculo, quanto mais próximo de 1,0 for o resultado, mais eficiente é o datacenter em termos energéticos. Jesus (2020) explica que a utilização correta do PUE bem como dos DCIM, além do uso de técnicas de centralização e virtualização de servidores, pode reduzir em até $50 \%$ o consumo de energia elétrica nestes ambientes.

Compreendendo o datacenter como uma central de processamento e armazenamento de dados em sistemas ativos de rede e tendo em vista que o eixo tecnológico Informação e Comunicação - do qual o curso técnico em MSI faz parte - prevê o estudo de "tecnologias relacionadas a infraestrutura e processos de comunicação e processamento de dados e informações" (BRASIL, 2016, p. 97), é lícito pressupor que a formação técnica do curso em pauta nesta pesquisa aborde as particularidades deste sistema computacional. Entretanto, o acentuado valor percentual verificado no item 21 à opção de maior significação negativa, expressa que os egressos pesquisados podem até ter tido alguma aproximação teórica a respeito da sustentabilidade ambiental em datacenters (vide item 15 da tabela 3 ) mas certamente não Ihes foram dadas oportunidades para o exercício prático deste tema.

Haja vista o fato de a virtualização ser um tópico comumente previsto nos projetos pedagógicos do curso técnico em MSI (SANTOS, 2016; JESUS, 2020), é surpreendente a majoritária inabilidade dos egressos pesquisados para com esse tema. Deste modo, mesmo com o item 13 apontando para um domínio insuficiente da maioria dos novos técnicos em relação a este conteúdo, não era esperada uma porcentagem tão negativa como a observada na assertiva 23.

O item 23 também enseja o mapeamento das habilidades dos egressos no que concerne à manipulação dos resíduos de equipamentos elétricos e eletrônicos. Em conformidade com os valores apresentados, na tabela 3, aos itens referentes a essa categoria de ação da TI Verde, foi constatado que, no geral, os egressos do IFS Campus Socorro não exibiram conhecimentos e opiniões consistentes sobre os REEE. Por ser um curso que lida diretamente 
com peças de reposição, conserto, diagnóstico preventivo do computador e consequente descarte ou reaproveitamento das peças (SANTOS, 2016), deverse-ia haver um cenário diferente do existente. Porém, a insuficiência teórica revelada pela maioria dos egressos neste tema encontra correspondência no item 24, indicando que as técnicas de manejo sustentável com o lixo eletrônico certamente não são praticadas de maneira adequada no curso em questão.

Similarmente à redução dos REEE, a economia de papel requer do profissional de $\mathrm{TI}$ algumas intervenções específicas as quais Lunardi, Simões e Frio (2014) exemplificam: terceirização de impressões; monitoramento de impressões; digitalização de documentos; impressão duplex (frente-e-verso); consolidação de impressoras; técnicas de utilização de impressoras multifuncionais. A despeito da importância do tema, os itens 25 e 26 revelaram que poucos egressos estão aptos a desenvolverem tarefas específicas voltadas à redução do gasto com papel. Conquanto esses dados possam, juntos com os itens 10 e 11 da tabela 3, indicar um tratamento insatisfatório deste tema no percurso formativo dos técnicos, é novamente imprescindível aludir à tabela 2 e lembrar que esses egressos talvez não possuam poder aquisitivo necessário para ter uma impressora, tampouco emprego que os permita contato com esse instrumento. Evidentemente que, nesse contexto, as habilidades seriam prejudicadas.

Por fim, 0 item 27 remete às normas, leis, certificações e regulamentações ambientais que atestam os produtos de $\mathrm{TI}$ menos agressivos ao meio ambiente. Apesar de serem dispositivos fundamentais para a orientação dos consumidores e usuários em geral, a distribuição percentual neste item mostrou que apenas uma minoria dos egressos recorre a esse expediente. O resultado leva a crer que, se a dimensão legal da TI Verde é realmente tratada no curso técnico de MSI do IFS Campus Socorro, por algum motivo ela não é traduzida pelos egressos como uma habilidade específica de sua profissão.

\section{Atitudes socioambientais em TI}

As atitudes aqui analisadas são representadas pelas práticas cotidianas em TI Verde ressignificadas pelos atributos culturais e profissionais de quem as executa. Mantendo o padrão estabelecido neste artigo, foram destacadas, na tabela 5 , as duas maiores porcentagens de cada item descrito. 
Tabela 5: Frequência relativa (\%) das respostas referentes às atitudes socioambientais em TI dos egressos pesquisados

\begin{tabular}{|c|c|c|c|c|c|}
\hline ITENS & $\mathbf{N}^{1}$ & $\overline{\mathbf{R}^{2}}$ & $\overline{A V^{3}}$ & $\overline{F^{4}}$ & $\overline{S^{5}}$ \\
\hline $\begin{array}{l}\text { 28. Deixo de comprar produtos } \\
\text { eletrônicos/tecnológicos de empresas } \\
\text { que tenham feito algo prejudicial à } \\
\text { sociedade, ao meio ambiente ou a } \\
\text { comunidades próximas. }\end{array}$ & $33,4 \%$ & $37,2 \%$ & $17,9 \%$ & $7,7 \%$ & $3,8 \%$ \\
\hline $\begin{array}{l}\text { 29. Desligo os equipamentos que não estão } \\
\text { sendo utilizados. }\end{array}$ & $2,6 \%$ & $5,1 \%$ & $10,2 \%$ & $25,7 \%$ & $56,4 \%$ \\
\hline $\begin{array}{l}\text { 30. Procuro informar/sensibilizar outras } \\
\text { pessoas sobre o uso racional de energia } \\
\text { elétrica. }\end{array}$ & $6,4 \%$ & $19,2 \%$ & $28,2 \%$ & $26,9 \%$ & $19,2 \%$ \\
\hline $\begin{array}{l}\text { 31. Troco meus equipamentos eletrônicos } \\
\text { por outros atualizados. }\end{array}$ & $23 \%$ & $30,8 \%$ & $29,5 \%$ & $11,5 \%$ & $5,1 \%$ \\
\hline $\begin{array}{l}\text { 32. Quanto aos resíduos de equipamentos } \\
\text { elétricos e eletrônicos (pilhas, baterias e } \\
\text { equipamentos quebrados), costumo } \\
\text { reaproveitá-los, doá-los ou mandá-los } \\
\text { para a coleta seletiva apropriada. }\end{array}$ & $23 \%$ & $20,5 \%$ & $29,5 \%$ & $16,7 \%$ & $10,2 \%$ \\
\hline 33. Evito a impressão em papel. & $16,7 \%$ & $17,9 \%$ & $41 \%$ & $10,2 \%$ & $14,1 \%$ \\
\hline $\begin{array}{l}\text { 34. Reaproveito os impressos como } \\
\text { rascunho. }\end{array}$ & $7,7 \%$ & $10,2 \%$ & $11,5 \%$ & $26,9 \%$ & $43,6 \%$ \\
\hline $\begin{array}{l}\text { 35. Reutilizo os cartuchos de tinta das } \\
\text { impressoras sob } \\
\text { responsabilidade. }\end{array}$ & $25,6 \%$ & $34,6 \%$ & $16,7 \%$ & $12,8 \%$ & $10,2 \%$ \\
\hline $\begin{array}{l}\text { 36. Participo ou promovo ações } \\
\text { socioambientais no meu bairro, no IFS, } \\
\text { em alguma escola ou empresa. }\end{array}$ & $53,8 \%$ & $16,7 \%$ & $15,4 \%$ & $7,7 \%$ & $6,4 \%$ \\
\hline $\begin{array}{l}\text { 37. Procuro conhecer diferentes formas de } \\
\text { preservação ambiental e me capacitar } \\
\text { para agir sustentavelmente enquanto } \\
\text { cidadão e profissional. }\end{array}$ & $28,2 \%$ & $30,8 \%$ & $25,6 \%$ & $7,7 \%$ & $7,7 \%$ \\
\hline
\end{tabular}

1- Nunca; 2- Raramente; 3- Às vezes; 4- Frequentemente; 5- Sempre.

Fonte: Elaborado pelo próprio pesquisador.

Santos et al. (2017) explicam que as atitudes socioambientais exercidas no domínio do gerenciamento de energia elétrica são norteadas por preferências completas e transitivas nas quais o decisor - em nosso caso, o egresso do curso técnico de MSI do IFS Campus Socorro - está ciente das alternativas e, por intermédio de seus conhecimentos e de suas habilidades, pode calcular a probabilidade de sucesso de cada uma delas. Isto é, o acervo de saberes e as ações específicas do fazer profissional serão encarregados de impulsionar a postura cidadã nas avaliações e tomadas de decisão em função das consequências que lhes são concernentes. 
Em relação aos computadores, a redução do consumo de energia elétrica pode ser feita através da adoção de hábitos simples como, por exemplo, desativar o monitor quando ele não estiver em uso ou desligar corretamente toda a máquina ao final do período de trabalho ou das atividades estudantis. As frequências relativas dos itens 29 e 30 sugerem que os egressos procuram transformar seus conhecimentos e habilidades em atitudes. Contudo, analisando essas mesmas porcentagens à luz do quadro majoritariamente adverso referente aos entendimentos e procedimentos dos investigados acerca do gerenciamento de energia elétrica em $\mathrm{TI}$ - exibidos respectivamente pelas tabelas 3 e 4 -, presume-se que ainda é necessária uma maior sensibilização destes técnicos para que suas condutas socioambientais sejam significativas às suas identidades e à sua formação.

Reforçando essa interpretação, é primacial salientar que as atitudes em favor do meio ambiente caracterizadas pela "ausência de reflexão que permita a compreensão contextual e articulada das causas e consequências dos problemas ambientais" (LAYRARGUES; LIMA, 2014, p. 32), costumam ser representadas por um conjunto de ações pragmáticas e superficiais que encontram-se em sentido contrário ao da formação humana integral. A ausência de reflexão é derivada, não só da convicção na neutralidade científico-tecnológica, mas também da condescendência inconsciente às limitações impostas pela lógica do capital. A partir dos dados da tabela 3, foi permitido inferir que esses atributos estão presentes na maior parte dos egressos. Dessa forma, é factível depreender que os resultados observados nos itens 29 e 30 podem evidenciar, tão somente, medidas de viabilidade econômica empregadas pelos pesquisados, passando ao largo da omnilateralidade.

Quanto às atitudes socioambientais pertinentes ao lixo eletrônico, é possível citar a reutilização. Nela, o indivíduo dá, aos aparelhos ou às peças, destinações diferentes daquelas para as quais eles foram projetados, contribuindo com a diminuição do descarte indevido de REEE. Uma segunda atitude reside em doar esses artefatos para cooperativas de reciclagem ou demais instituições correlatas, a fim de que Ihes sejam aplicados métodos de triagem, recondicionamento, armazenagem e reaproveitamento dos componentes informáticos. Destarte, no enquadramento dessas ações, os valores percentuais verificados no item 32 parecem reproduzir os parcos conhecimentos e habilidades socioambientais alusivos ao tratamento dos REEE previamente apresentados pela maioria dos egressos pesquisados.

Ratificando e complementando a crítica de Antunes (2009) no tocante às objetivações fetichizadas que são determinadas ao mundo do trabalho pelo capital, Layrargues e Lima (2014) informam que, no cenário hegemônico da economia de mercado e do sistema produtivo baseado no consumismo, o padrão de consumo de bens eletrônicos desponta, não só como um fator de bem estar e distinção social, mas também como um dos principais causadores do significativo aumento na geração de lixo eletrônico. Observando as respostas ao item 31, nota-se que, no geral, os egressos não compartilham do 
modelo consumista ora relatado. No entanto, é passível de dedução que essas respostas sejam fundamentalmente justificadas pelo recorte socioeconômico dos egressos (tabela 2), evidenciando o aspecto financeiro como um provável obstáculo, para a maioria desses novos técnicos, na obtenção regular de instrumentos representativos da inovação tecnológica.

No que se refere às atitudes socioambientais vinculadas à utilização racional de papel, enquanto o item 34 apresentou uma distribuição percentual que denota um ímpeto positivo da maior parte dos egressos, os itens 33 e 35 foram em direção oposta. Recorrendo-se, mais uma vez, ao perfil socioeconômico dos egressos e aos seus conhecimentos, opiniões e habilidades anteriormente discutidos, percebe-se que, não obstante seja necessário sensibilizá-los mais profundamente sobre esse tema, é também plausível considerar a flutuação desses dados como decorrente das condições sociais e econômicas da maioria dos investigados. Conjectura-se que essas condições, tanto os impelem a adotar estratégias de parcimônia financeira (item 34), como também Ihes dificultam o acesso, laboral ou privado, a serviços de impressão (itens 33 e 35).

Medeiros (2014) afirma que toda relação de consumo, por menor que seja, gera um impacto ambiental. Com a fabricação e o uso de equipamentos de Tecnologia da Informação não é diferente. Os efeitos significativos da TI no meio ambiente devem ser analisados levando em consideração os mais variados aspectos do problema, haja vista que as adversidades podem ser irreversíveis tanto ao meio ambiente como à população. Concebe-se, portanto, a postura crítico-reflexiva quanto às circunstâncias humanas e ambientais nas quais os produtos de TI encontram-se envolvidos como uma atitude socioambiental. Apesar disso, as frequências relativas observadas no item 28 demonstram que mais da metade dos egressos pesquisados exercem um comportamento oposto a esse propósito, o que provavelmente indica uma reprodução atitudinal dos posicionamentos declarados no item 4 da tabela 3 e no item 27 da tabela 4.

Por último, é importante sublinhar que a TI Verde, à guisa da formação humana integral, prevê como atitude precípua o engajamento na transformação da realidade local mediante o exercício, na prática, de novas vivências relacionadas às influências socioambientais do desenvolvimento tecnológico. De acordo com Paula (2016), a intervenção na realidade auxilia a percepção crítica sobre o meio ambiente na medida em que vai ao encontro da complexidade das inter-relações que compõem o todo. De modo inverso a esse entendimento e possivelmente refletindo as incertezas observadas nos itens 16 e 17 da tabela 3 , os itens 36 e 37 apontaram que a maioria dos egressos possuem raro ou nenhum intuito na capacitação e na participação em ações de sustentabilidade ambiental. Contrariamente ao que se defende em uma abordagem crítica, percebe-se uma forte tendência ao não cumprimento prático da $\mathrm{TI}$ Verde ou ao desenvolvimento de ações isoladas, limitadas ao comportamento individual de cada um e desconectadas da realidade socioambiental em que se está inserido.

Revbea, São Paulo, v.16, № 1: 240-262, 2021.

revista brasileira educação ambiental 


\section{Considerações finais}

Apesar de os dados obtidos estarem também condicionados às circunstâncias sócio-econômico-culturais dos egressos investigados, o presente estudo demonstrou que esses sujeitos de pesquisa apresentaram, em linhas gerais, um perfil socioambiental caracterizado por níveis insatisfatórios de conhecimentos, opiniões, habilidades e atitudes quanto a conceitos e práticas de sustentabilidade ambiental relacionados direta ou indiretamente ao universo da TI. Isso indica que, ao longo da formação do técnico em Manutenção e Suporte em Informática do IFS Campus Socorro, há uma escassez de práticas pedagógicas consistentes associadas ao potencial integrador dos conteúdos pertencentes à TI Verde.

Tal cenário evidencia a necessidade em formar trabalhadores dotados de fundamentos éticos e sociais relacionados aos processos produtivos e propícios a lhes assegurar autonomia intelectual e profissional baseada no conhecimento das inter-relações entre Ciência, Tecnologia, Sociedade e Ambiente. Assim, para a materialização desse panorama, torna-se precípuo que o itinerário formativo do curso técnico subsequente de Manutenção e Suporte em Informática do IFS Campus Socorro contemple temas, instrumentos didáticos e estratégias de ensino que permitam a contextualização sugerida.

\section{Referências}

ACAR, H. Software development methodology in a Green IT environment. Lyon, f. 120, 2017. Tese (Spécialité de doctorat: Informatique) UNIVERSITÉ DE LYON, 2017.

ANTUNES, R. Os Sentidos do Trabalho: Ensaio sobre a afirmação e a negação do trabalho. 2. ed. São Paulo: Boitempo Editorial, 2009. 287 p.

ARAÚJO, R.M.L.; FRIGOTTO, G. Práticas pedagógicas e ensino integrado. Revista Educação em Questão. Natal, v. 52, n. 38, p. 6180, mai./ago. 2015.

AULER, D. Enfoque Ciência-Tecnologia-Sociedade: pressupostos para o contexto brasileiro. Ciência \& Ensino. Campinas, v.1, número especial, s/p, nov. 2007.

BATISTA, W.S. TI Verde: processo de gestão de descarte de equipamentos eletrônicos de informática na Universidade Federal de Rondônia. Porto Velho, f. 155, 2018. Dissertação (Mestrado Profissional em Administração Pública) UNIVERSIDADE FEDERAL DE RONDÔNIA, 2018.

BRASIL. Lei n. 9.795 de 27 de abril de 1999. Diário Oficial da União. Brasília, 28 de abril de 1999.

BRASIL. Ministério da Educação. Secretaria de Educação Profissional e Tecnológica. Educação Profissional Técnica de Nível Médio Integrada ao Ensino Médio. Documento Base. Brasília/DF: MEC, 2007. 59p. 
BRASIL. Lei n. 11.892 de 29 de dezembro de 2008. Diário Oficial da União. Brasília, 30 de dezembro de 2008.

BRASIL. Ministério da Educação. Conselho Nacional de Educação. Resoluçãon. 2 de 15 de junho de 2012. Diário Oficial da União. Brasília: 18 de junho de 2012.

BRASIL. Ministério da Educação. Secretaria de Educação Profissional e Tecnológica. Catálogo Nacional de Cursos Técnicos. Brasília, Brasília/DF: MEC, 2016. 289p.

DIAS, G.F. Influência de macro e micro fatores na adoção de práticas de TI Verde em instituições de Ensino Superior brasileiras: uma pesquisa à luz da Teoria da Crença-Ação-Resultado. Natal, f. 131, 2015. Dissertação (Mestrado em Administração) - UNIVERSIDADE FEDERAL DO RIO GRANDE DO NORTE, 2015.

GASPARIN, J.L. Uma didática para a Pedagogia Histórico-Crítica. 5. Ed. Campinas: Autores Associados, 2015. 190p.

JESUS, L.A.F. Guia Didático para o Ensino de TI Verde: uma proposta integradora à luz da Pedagogia Histórico-Crítica. Aracaju: ProfEPT / Instituto Federal de Sergipe, 2020. $111 \mathrm{p}$.

LAYRARGUES, P. P.; LIMA, G.F.C. As macrotendências político-pedagógicas da Educação Ambiental brasileira. Ambiente \& Sociedade. São Paulo, v. 17, n. 1, p. 23-40, jan./mar. 2014.

LUNARDI, G.L.; SIMÕES, R.; FRIO, R.S. TI Verde: uma análise dos principais benefícios e práticas utilizadas pelas organizações. Revista Eletrônica de Administração, Porto Alegre, v. 20, n. 3, p. 1-30, jan./abr. 2014.

MARCONI, M.A.; LAKATOS, E.M. Técnicas de pesquisa: planejamento e execução de pesquisas, amostragens e técnicas de pesquisa, elaboração, análise e interpretação de dados. 7. Ed. São Paulo: Atlas, 2015. 277p.

MEDEIROS, J. Tecnologia da Informação Verde (TI Verde), uma abordagem sobre a Educação Ambiental e a sustentabilidade na Educação Profissional e Tecnológica. Joinville,f. 301, 2014. Dissertação (Mestrado em Educação) UNIVILLE, 2014.

MURUGESAN, S. Making IT Green. IT Professional. Los Alamitos, v. 12, n. 2, p. 4-5, mar. 2010.

PACHECO, E. Institutos Federais: uma revolução na educação profissional e tecnológica. In: PACHECO, E. Institutos Federais: uma revolução na educação profissional e tecnológica. Brasília/São Paulo: Editora Moderna, 2011. 120 p. cap. 2, p. 13-32.

PAULA, J.L. Educação Ambiental como elemento necessário à formação integral: trilhando caminhos possíveis na educação profissional. Natal, f. 194, 2016. Dissertação (Mestrado em Educação Profissional) - Instituto Federal de Educação, Ciência e Tecnologia do Rio Grande do Norte, 2016.

revista brasileira educação ambiental 
QUEIROZ, C.T.A.P.; CARVALHO, M.E.P.; MOREIRA, J.A. Gênero e inclusão de jovens mulheres nas Ciências Exatas, nas Engenharias e na Computação. 18을. REDOR. 2014. Anais eletrônicos... Recife, 2014. 17 p. Disponível em: $<$ http://www.ufpb.br/evento/index.php/18redor/18redor/paper/viewFile/2076/85 5> Acesso em: 17 set. 2020.

RAMOS, M. Possibilidades e desafios na organização do currículo integrado. In: FRIGOTTO, G.; CIVATTA, M.); RAMOS, M. (Orgs.). Ensino médio integrado: concepção e contradições. 3. ed. São Paulo: Cortez, 2012. 175 p. cap. 4, p. 107-128.

REIS, E.A.; REIS, I.A.; Análise Descritiva de Dados. 1. ed. Belo Horizonte: Universidade Federal de Minas Gerais, 2002. 64 p. (Relatório Técnico do Departamento de Estatística da UFMG).

SANTOS, L.C.P. Resíduo eletrônico: perspectiva ambiental das ações na formação profissional no Instituto Federal de Sergipe. São Cristóvão, f. 139, 2016. Tese (Doutorado em Desenvolvimento e Meio Ambiente) UNIVERSIDADE FEDERAL DE SERGIPE, 2016.

SANTOS, L.C.P. FABRIS, T.A.; FERREIRA L.J.; BITENCOURT, D.V. Comportamento no consumo de energia elétrica pelos alunos em direção a racionalização consciente. Revista Expressão Científica. Aracaju, v. 1, n. 1, p. 39-51, jan./jun. 2017.

SILVA, A.R.S. Lixo Eletrônico: de problema ambiental a fator de promoção do desenvolvimento. Franca, f. 102, 2018. Dissertação (Mestrado Desenvolvimento Regional) - Centro Universitário Municipal de Franca, 2018. 